\title{
Influência do choque térmico por resfriamento brusco do concreto após exposição a elevadas temperaturas em simulação de incêndio
}

\section{Influence of thermal shock by brush cooling of concrete in fire situations}

\begin{abstract}
Adenilson Roberto Coelho ${ }^{1}$, Geórgia Cristina Roveda Campos ${ }^{1}$, Carine Cardoso dos Santos ${ }^{1}$, Helena Ravache Samy Pereira ${ }^{1}$,
\end{abstract}

Tássia Furlaneto ${ }^{1}$

\footnotetext{
${ }^{1}$ Centro Universitário Católica de Santa Catarina - Rua Visconde de Taunay, $\mathrm{n}^{\circ}$ 427, Joinville, Santa Catarina, Brasil. E-mail: adenilson_rcoelho@hotmail.com, georgia.campos@catolicasc.org.br, helena.pereira@ catolicasc.org.br
}

\section{RESUMO}

Em situações de diferença abrupta de temperatura, como os incêndios, as estruturas devem suportar ao choque térmico. Portanto, esse artigo tem como objetivo avaliar o comportamento do concreto submetido às elevadas temperaturas e o posterior resfriamento brusco. Para isso analisou-se este efeito nas resistências características com fck de 25, 35 e 40MPa. As análises observaram as perdas de resistência, coloração e presença de fissuras nos concretos. Para isso, os corpos de prova foram submetidos às temperaturas de $300,600,900$ e $1200^{\circ} \mathrm{C} \mathrm{du}-$ rante 90 minutos e depois resfriados. As resistências características de compressão dos corpos de prova foram comparadas ao concreto de referência e aos dados da bibliografia, obtendo-se a perda de resistência dos concretos resfriados bruscamente. Os resultados obtidos mostram que os concretos com fck de 35 e $40 \mathrm{MPa}$ apresentam maior perda de resistência quando comparados ao concreto com fck de $25 \mathrm{MPa}$. Entretanto, nas temperaturas de 900 e $1200^{\circ} \mathrm{C}$, o percentual de perda é igual ao concreto com fck de $25 \mathrm{MPa}$. Isso remete ao fato, de que quanto mais resistente for o concreto, e submetido à variação de temperatura, maior será a perda percentual e a incidência do surgimento de fissuras quando aquecido e resfriado.

Palavras-chave: Temperatura. Incêndio. Resfriamento. Resistência. Concreto. Fissuras.

\begin{abstract}
In situations of abrupt temperature differences, as the residential fires, these structures must support the thermal chock. Thus, this is paper aims to assess the behavior of concrete exposed to high temperatures and subsequent abrupt cooling. For this we analyzed this effect on the characteristic resistences with fck of 25,35 and $40 \mathrm{MPa}$. The analyzies observed the resistence losses and the colorations of the concretes. The samples were submitted to the temperature of $300,600,900$ and $1200^{\circ} \mathrm{C}$ for 90 minutes and tempered in freshwater. The strength were compared to the reference samples and to the theory to estimate the strength of the concrete exposed to abrupt cooling. The results show that concretes with $\mathrm{F}_{\mathrm{ck}}$ equal to 35 and $40 \mathrm{MPa}$ present lower strength when compared to the concrete with fck equal to $25 \mathrm{MPa}$. On the other hand, at 900 and $1200^{\circ} \mathrm{C}$, the percentage of strength lost is the same as $25 \mathrm{MPa}$. However, at temperatures of 900 and $1200^{\circ} \mathrm{C}$, the loss percentage is equal to the concrete with fck of $25 \mathrm{MPa}$. That is, the higher the strength is, the higher the lost rate and the higher the incidence appearance of craks when heated and cooled.
\end{abstract}

Keywords: Temperature. Fire. Abrupt cooling. Strength. Concrete. Fissures.

\section{INTRODUÇÃO}

A preocupação pós-incêndio com as estruturas de concreto é relevante, uma vez que, quando expostas a temperaturas elevadas, como 1200 e $2000^{\circ} \mathrm{C}$ podem desenvolver diversos problemas micro e macro estruturais, alterando suas propriedades físico-químicas e mecânicas, podendo reduzir a resistência e até mesmo colapsar a estrutura [9, 20, 24]. Por menor que seja a difusividade térmica do concreto, a sua estabilidade relaciona-se com a microestrutura, necessitando de verificações minuciosas após a ocorrência de incêndio, considerando 
tanto a exposição em elevadas temperaturas quanto o método de resfriamento [22, 12]. Um exemplo de exposição à elevadas temperaturas, foi com a colisão da aeronave Airbus contra uma edificação em São Paulo, no aeroporto de Congonhas. O impacto, explosão e calor contribuíram para o colapso estrutura [5, 14]. Portanto, o artigo busca avaliar o comportamento dos concretos de fck 25, 35, e 40MPa quando aquecidos em 300, 600, 900 e $1200^{\circ} \mathrm{C}$ e resfriados bruscamente, simulando a atuação dos bombeiros no combate a incêndio.

O conhecimento da ação do fogo, dos efeitos da temperatura e dos métodos de resfriamento nas estruturas de concreto é relevante para determinar o tempo de permanência dos ocupantes dentro da edificação, considerando-se o possível colapso estrutural $[6,7,28]$. As temperaturas elevadas de incêndio e o resfriamento brusco interferem diretamente na resistência do concreto, minimizando a sua funcionalidade, podendo trazer consequências fatais às pessoas que estão in loco e aos bombeiros durante os resgates, sendo necessária a avaliação detalhada da estrutura. O resfriamento brusco da estrutura é o método usual de combate a incêndio utilizado pelo Corpo de Bombeiros com a sobreposição de água sobre o material em combustão [4, 13]. Sendo o fogo uma reação em cadeia que necessita de combustível, calor e oxigênio para manter-se ativo, ao retirar-se um de seus componentes, como o calor, a reação minimiza-se [11,30].

O fenômeno de flashover é o momento em que ocorre à temperatura de ignição de todo o material combustível presente, causando uma queima súbita e generalizada, sendo o responsável por uma das fases de maior propagação do fogo $[3,26]$. O incêndio experimental ou incêndio padrão apresenta uma taxa de aumento de temperatura $(\mathrm{T})$ pré-definida ao longo do tempo $(\mathrm{t})$, permitindo a reprodução do incêndio real em um determinado compartimento. Nos incêndios padrões, os picos de máximas temperaturas encontram-se aproximadamente aos 90 e 120 minutos de exposição [1, 26, 27].

$\mathrm{O}$ concreto quando submetido ao aquecimento apresenta diversas fissuras e, consequentemente, perdas de resistência [8, 17]. As fissuras ocorrem devido a pressões internas e a desidratação dos silicatos de cálcio hidratados $(\mathrm{C}-\mathrm{S}-\mathrm{H})$. Isso pode fazer com que fragmentos de concreto desprendam-se. Este efeito é conhecido como explosive spalling, onde os agregados ricos em sílica, tais como os granitos, arenitos, gnaisses entre outros, quando superaquecidos proporcionam manifestações patologias no concreto [15, 23]. As patologias são em virtude de sua expansão, ocasionando o spalling, que nada mais é do que o lascamento do concreto [18].

$\mathrm{O}$ explosive spalling, resultado do surgimento de fissuras, faz com que ocorra perda de partes fragmentadas do concreto, comprometendo sua resistência e expondo a armadura ao contato direto com o fogo [27]. O aquecimento gradativo do aço instaura o decaimento das propriedades mecânicas da armadura, ocorrendo desta forma a perda da função estrutural. A utilização de fibras de poliproileno no concreto minimizam os efeitos do spalling no concreto $[9,10,31]$.

Quando a estrutura de concreto é exposta aos $100^{\circ} \mathrm{C}$ a água evapora, sendo transportada para as zonas mais frias, formando uma camada saturada. A camada obstrui a passagem de vapores de água, desenvolvendo pressões internas no concreto, empurrando-os de dentro para fora, contribuindo para o surgimento de fissuras e lascamentos [2, 31].

Após o efeito do aquecimento, o método de resfriamento brusco também altera as propriedades físicoquímicas na pasta de cimento Portland. O processo de resfriamento pode reidratar o cimento, formando novos componentes cristalizados. Estes componentes também se expandem e formam mais microfissuras devido à sua cristalização, formando o spalling na zona de transição entre os agregados e o concreto [12, 15, 25].

Lima (2005) apud Silva [13] observou que até $400^{\circ} \mathrm{C}$ os concretos expostos a elevadas temperaturas não apresentam grandes perdas de resistência. No entanto, o autor verifica a perda de resistência e o aumento de tamanho dos poros no concreto quando submetidos a temperaturas acima de $450^{\circ} \mathrm{C}$. A água livre contida no concreto começa a evaporar em $100^{\circ} \mathrm{C}$ e desidrata o C-S-H. Além disso, a desidratação, a quebra do C-S-H e a evaporação proporcionam novos poros, originando novas fissuras e a retração acentuada [16, 29].

A Tabela 1, adaptada de [20,17], apresenta os principais efeitos físico-químicos resultantes do aquecimento e do aumento de temperatura no concreto.

Tabela 1: Efeitos físicos-químicos no concreto conforme a variação de temperatura.

\begin{tabular}{c|c}
\hline Temperatura $\left({ }^{\mathbf{0}} \mathbf{C}\right)$ & Efeitos físicos-químicos no concreto \\
\hline $100-500$ & Desidratação do C-S-H e possíveis danos, como o explosive spalling \\
\hline 200 & Retração por desidratação do C-S-H e dilatação dos agregados \\
\hline $300-400$ & Redução da água, formação de silicatos anidros, fissuras \\
\hline $400-500$ & Retração acentuada por desidratação do C-S-H \\
\hline $500-600$ & Desidratação do C-S-H mais rápida \\
\hline $600-700$ & Transformação de outros agregados. O CaCO $\mathrm{O}_{3}$ transforma-se em $\mathrm{C}_{\mathrm{a}} \mathrm{O}$ e libera $\mathrm{CO}_{2}$ \\
\hline
\end{tabular}




\begin{tabular}{c|c}
\hline 800 & Retração por perda da água combinada da torbemorita \\
870 & Expansão do quartzo na transformação de beta em tridimita. \\
\hline 900 & Perda total da água de hidratação do concreto \\
\hline 1200 & Início da deterioração \\
\hline
\end{tabular}

De acordo com os referenciais teóricos $[15,12]$, o concreto quando submetidos à temperaturas além de $600^{\circ} \mathrm{C}$, sofre alterações no aspecto visual, ou seja, o alteração na coloração e aparecimento de fissuras na ordem de 0,05 a $0,1 \mathrm{~mm}$. No instante em que ocorre o flashover, o interior da edificação apresenta-se com temperatura, em geral, na ordem de 1000 a $1200^{\circ} \mathrm{C}$, apresentando uma coloração amarelo claro do concreto e percentual de resistência menor, abaixo do comum, com perda aproximada de $90 \%$ [19, 32].

Considerando a temperatura ambiente até $300^{\circ} \mathrm{C}$, o concreto mantem a resistência estimada aos 28 dias de cura, com uma pequena variação em percentuais da resistência característica. Na medida em que a temperatura no interior da edificação cresce até $600^{\circ} \mathrm{C}$, a resistência do concreto cai em $50 \%$, para tanto, a mesma pode chegar de 20 a $5 \%[19,21]$.

$\mathrm{O}$ artigo não apresenta ensaios com microscopia eletrônica de varredura (MEV) e difração de raio $\mathrm{x}$ (DRX), sendo apenas analisada as perdas de resistência à compressão através do ensaio de resistência, coloração e presença de fissuras através de análise visual dos concretos. Estudos mais detalhados na microestrutura do concreto não foram realizados, pois não era o objetivo de pesquisa.

\section{MATERIAIS E MÉTODOS}

Como procedimento experimental, foram confeccionados 45 Corpos de Prova (CP's), sendo 9 CP's de referência, ou seja, não aquecidos. Para os ensaios comparativos produziram-se $36 \mathrm{CP}$ 's nas quais foram submetidos durante 90 minutos nas temperaturas de $300,600,900$ e $1200^{\circ} \mathrm{C}$.

Às quantidades de CP's e as temperaturas de exposição durante 90 minutos são expressas na Tabela 2.

Tabela 2: Quantidade de corpos de prova para cada fck e variação de temperatura de exposição.

\begin{tabular}{c|c|c|c|c|c}
\hline $\begin{array}{c}\text { fck } \\
(\mathbf{M P a})\end{array}$ & $\begin{array}{c}\text { Referência } \\
\text { Quant. CP's }\end{array}$ & $\begin{array}{c}\mathbf{3 0 0}^{\circ} \mathbf{C} \\
\text { Quant. CP's }\end{array}$ & $\begin{array}{c}\mathbf{6 0 0}^{\circ} \mathbf{C} \\
\text { Quant. CP's }\end{array}$ & $\begin{array}{c}\mathbf{9 0 0}^{\circ} \mathbf{C} \\
\text { Quant. CP's }^{\prime}\end{array}$ & $\begin{array}{c}\mathbf{1 2 0 0}^{\circ} \mathbf{C} \\
\text { Quant. CP's }\end{array}$ \\
\hline 25 & 3 & 3 & 3 & 3 & 3 \\
\hline 35 & 3 & 3 & 3 & 3 & 3 \\
\hline 40 & 3 & 3 & 3 & 3 & 3 \\
\hline Total & 9 & 9 & 9 & 9 & 9 \\
\hline
\end{tabular}

A Tabela 3 apresenta as etapas para o procedimento experimental, sendo estes discriminados nos subitens no decorrer do capítulo. Foram realizados os seguintes ensaios: no estado fresco, sendo a de determinação do índice de consistência bem como a moldagem dos CP's; no estado endurecido, após o processo de aquecimento e resfriamento brusco, a resistência à compressão e análise da coloração e a presença de fissuras.

Tabela 3: Etapas do procedimento experimental.

\begin{tabular}{c|c}
\hline Etapas & Descrição \\
\hline 1 & Caracterização dos materiais \\
\hline 2 & Dosagem dos concretos com fck de 25, 35 e 40MPa \\
\hline 3 & Produção dos concretos, moldagem e cura em CP's \\
\hline 4 & Aquecimento e resfriamento brusco dos CP's \\
\hline 5 & Resistência à compressão, análise da coloração e presença de fissuras no concreto \\
\hline
\end{tabular}

\subsection{Caracterização dos materiais constituintes e dosagem do concreto}

Os agregados foram caracterizados com relação à sua massa específica, segundo a NBR NM 52 (ABNT, 2009), teor de material pulverulento pela NBR 46 (ABNT, 2003) e granulometria NBR 248 (ABNT, 2003).

Após a caracterização dos agregados, calculou-se a dosagem do concreto, obtendo os percentuais dos agregados, a água e o cimento Portland composto, em massa, conforme apresentado na Tabela 4, de acordo com a Associação Brasileira de Cimento Portland (ABCP). O cimento utilizado foi o CP-II-Z com pozolana. A 
areia é a média, módulo de finura de $2,6 \mathrm{~mm}$ e massa específica de $2,65 \mathrm{~g} / \mathrm{cm}^{3}$, sendo o percentual de material pulverulento entre 2,5 a 1,5\%. A brita é do tipo 1, com dimensão máxima característica de 19mm.

Tabela 4: Traço para o concreto com método de dosagem da ABCP.

\begin{tabular}{c|c|c|c}
\hline Material & 25MPa & 35MPa & 40MPa \\
\hline Cimento $(\mathrm{kg})$ & 1,000 & 1,000 & 1,000 \\
\hline Areia $(\mathrm{kg})$ & 2,276 & 1,761 & 1,503 \\
\hline Água $(\mathrm{l})$ & 0,600 & 0,500 & 0,450 \\
\hline Brita $(\mathrm{kg})$ & 3,300 & 2,750 & 2,475 \\
\hline
\end{tabular}

\subsection{Corpos de prova de concreto e slump test}

A trabalhabilidade do concreto foi medida através de ensaio do índice de consistência slump test, conforme a NBR NM 67 (ABNT, 1998), sendo este realizado no estado fresco, avaliando-se a fluidez e a proporção ideal para a relação água/cimento $(\mathrm{a} / \mathrm{c})$. Os dados obtidos no ensaio de slump test dos concretos estão na Tabela 5.

Tabela 5: Ensaio de slump test dos concretos.

\begin{tabular}{c|c|c|c}
\hline Resistência característica (fck) & 25MPa & 35MPa & 40MPa \\
\hline Slump test $(\mathrm{cm})$ & $9,80 \pm 0,10$ & $9,70 \pm 0,10$ & $9,10 \pm 0,10$ \\
\hline
\end{tabular}

\subsection{Aquecimento dos CP's e resfriamento brusco}

$\mathrm{O}$ aquecimento foi realizado em forno industrial Jung, modelo 5753, sendo a temperatura máxima de $1200^{\circ} \mathrm{C}$, com capacidade para $180 \mathrm{~kg}$ e taxa de aquecimento programado para $5^{\circ} \mathrm{C} / \mathrm{min}$. As temperaturas foram determinadas com base em outros autores, sendo as temperaturas do flashover de 1000 a $1200^{\circ} \mathrm{C}[2,3,11,5,4]$.

Após submetidos às temperaturas por 90 minutos, os CP's foram resfriados bruscamente em tanque de concreto com água em temperatura ambiente, ficando submerso por 15 minutos, para simular a atuação das equipes de bombeiros em incêndios.

\subsection{Resistência à compressão do concreto, fissuras e coloração}

Os CP's depois de aquecidos e resfriados, foram analisadas a resistência à compressão na EMIC, modelo PC200CS, NO 11202, conforme descreve a NBR 5739 (ABNT, 2007), obtendo-se a resistência característica aos 28 dias de cura, dados em MPa.

Os resultados foram comparados aos dos referenciais teóricos e aos valores dos CP's de referência mantidos em temperatura ambiente. A presença de fissuras e a coloração dos CP's foram analisadas visualmente, tendo como referência trabalhos anteriores e os CP's não aquecidos, mantidos em temperatura ambiente.

\section{RESULTADOS}

\subsection{Resistência à compressão dos concretos e coloração}

Após serem submetidos às temperaturas de $300,600,900$ e $1200^{\circ} \mathrm{C}$ durante 90 minutos, os concretos com fck's de 25, 35 e 40MPa foram submetidos ao resfriamento brusco e posteriormente ao ensaio de resistência à compressão dos CP's. Os resultados das análises, com o desvio padrão e o percentual de perda em relação ao referencial estão descritos na Tabela 6.

Tabela 6: Resultado da resistência à compressão.

\begin{tabular}{c|c|c|c|c|c|c|c|c|c}
\hline \multirow{2}{*}{$\mathbf{T}\left({ }^{\circ} \mathbf{C}\right)$} & \multicolumn{4}{|c|}{ Resistência à compressão, desvio padrão e percentuais finais de resistência } \\
\cline { 2 - 10 } & fck de 25MPa & \multicolumn{3}{c|}{ fck de 35MPa } & \multicolumn{3}{c}{ fck deMPa 40MPa } \\
\cline { 2 - 10 } & fck & $\begin{array}{c}\text { Desvio } \\
\text { padrão }\end{array}$ & $\begin{array}{c}\% \\
\text { perda }\end{array}$ & fck & $\begin{array}{c}\text { Desvio } \\
\text { padrão }\end{array}$ & $\begin{array}{c}\% \\
\text { perda }\end{array}$ & fck & $\begin{array}{c}\text { Desvio } \\
\text { padrão }\end{array}$ & $\begin{array}{c}\% \\
\text { perda }\end{array}$ \\
\hline Referência & 22,02 & $\pm 0,88$ & 00,00 & 32,80 & $\pm 0,46$ & 00,00 & 38,41 & $\pm 0,84$ & 00,00 \\
\hline 300 & 15,20 & $\pm 2,39$ & 30,97 & 20,21 & $\pm 2,13$ & 38,39 & 21,33 & $\pm 0,79$ & 44,47 \\
\hline 600 & 7,94 & $\pm 0,88$ & 63,94 & 10,10 & $\pm 1,02$ & 69,26 & 10,01 & $\pm 0,50$ & 73,94 \\
\hline 900 & 1,64 & $\pm 0,24$ & 92,55 & 1,68 & $\pm 0,26$ & 94,88 & 2,03 & $\pm 0,34$ & 94,71 \\
\hline 1200 & 1,21 & $\pm 0,28$ & 94,51 & 1,49 & $\pm 0,83$ & 95,46 & 1,24 & $\pm 0,16$ & 96,77 \\
\hline
\end{tabular}


Observa-se que, com o aumento de temperatura, o percentual da perda de resistência aumentou, e, ao analisar cada fck, percebe-se que quanto maior é a resistência característica, mais perda de resistência ocorreu.

As médias do percentual de perdas da resistência característica dos fck's de 25, 35 e 40MPa discriminados anteriormente na Tabela 6, são apresentadas na Tabela 7, na coluna média do percentual de perdas.

Tabela 7: Percentual de perda de resistência médias dos fck's de 25, 35 e 40MPa.

\begin{tabular}{c|c}
\hline Temperatura $\left({ }^{\circ} \mathbf{C}\right)$ & $\begin{array}{c}\text { Média do percentual de perdas } \\
\text { Aquecimento + Resfriamento) }(\boldsymbol{\%})\end{array}$ \\
\hline Concreto de referência & 00,00 \\
\hline 300 & 37,94 \\
\hline 600 & 69,05 \\
\hline 900 & 94,05 \\
\hline 1200 & 95,58 \\
\hline
\end{tabular}

Verifica-se que nos CP's com fck de 25, 35 e 40MPa, o resfriamento brusco contribuiu para a perda de resistência, apresentando em $1200^{\circ} \mathrm{C}$, o percentual de perda de resistência em média de $95,58 \%$, se comparado ao valor inicial do concreto de referência. O processo de reidratação do C-S-H decorrente ao resfriamento brusco, assim como as alterações das propriedades mecânicas do concreto após aquecimento e resfriamento, contribuiu para a perda de resistência do concreto, principalmente aos concretos de maior resistência característica. A reidratação pode ter ocorrido nos concretos analisados, uma vez que os resultados são condizentes aos estudos já realizados, nas quais foram observadas as perdas e alterações [12,17].

Os dados analisados na Tabela 4 são apresentados na (Figura 1), onde é perceptível o decaimento da resistência com o aumento da temperatura no resfriamento brusco.

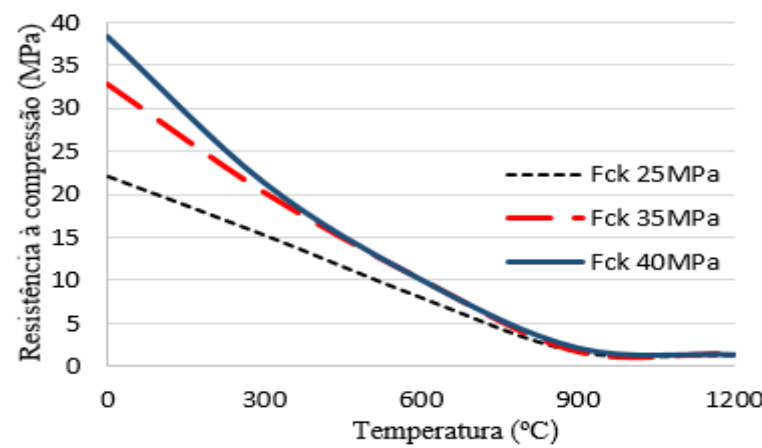

Figura 1: Perda de resistência versus aumento de temperatura e resfriamento brusco.

De acordo com o referencial teórico [12, 15, 17 e 19], em $100^{\circ} \mathrm{C}$ o concreto apresenta alterações físicoquímicas em suas propriedades. Esse efeito é decorrente das mudanças de temperatura e a desidratação do C-SH. Para os CP's com fck de 25, 35 e 40MPa, aos $300^{\circ} \mathrm{C}$ o concreto apresenta entre 30,97 e $44,47 \%$ respectivamente da sua resistência inicial. Aos $600^{\circ} \mathrm{C}$ a perda de resistência é maior, com percentual de perda entre 63,94 a 73,94\% nessa ordem, não sendo mais útil estruturalmente. Para temperaturas como $900^{\circ} \mathrm{C}$, o percentual de perda apresenta-se de 92,55 a $94,77 \%$ e, aos $1200^{\circ} \mathrm{C}$ a perda da resistência fica entre 94,51 e $96,77 \%$, ou seja, resistência quase nula.

Para os concretos com fck de 25 e $35 \mathrm{MPa}$ o percentual de perda é, em média de $34,68 \%$ em $300^{\circ} \mathrm{C}$ a $94,98 \%$ em $1200^{\circ} \mathrm{C}$. Portanto, em média, os fck's de 25 e $35 \mathrm{MPa}$ apresentam-se menor quando comparado com o concreto de fck 40MPa, uma vez que o fck 40MPa caracteriza-se por um percentual maior e não linear, variando o percentual de resistência de $44,47 \%$ em $300^{\circ} \mathrm{C}$ a $96,77 \%$ em $1200^{\circ} \mathrm{C}$. Isso pode estar relacionado a sua estrutura maciça, com menor presença de poros e menor fator água-cimento. Já os concretos com fck de 25 e $35 \mathrm{MPa}$, possuem maior quantidade de poros e água. Tais hipóteses são embasadas nos referenciais [12, 15, 16, $17,20]$.

Os percentuais de perda de resistência coincidem em $900^{\circ} \mathrm{C}$, ou seja, todos os concretos de 25,35 e $40 \mathrm{MPa}$, em $900^{\circ} \mathrm{C}$ apresentaram perdas consideráveis de resistência, média dos três concretos com percentual de $94,05 \%$ de perdas. Em virtude da maior quantidade de cimento para obtenção das resistências de fck 35 e 40MPa, o processo de reidratação é mais rápido no resfriamento brusco, formando agulhas de cristais e a rees- 
truturação do C-S-H, danificando ainda mais a estrutura de concreto após o aquecimento. Isso pode ser afirmado devido aos resultados coincidirem com estudos anteriores como $[6,12,16]$. Os resultados de perdas de resistência e aparências físicas são observados tanto nos concretos ensaiados quanto nos estudos realizados por $[15,16,17]$

A Tabela 8 apresenta a comparação do percentual de perda após o aquecimento e resfriamento brusco com as médias das perdas de resistência características dos fck's indicados na tabela anterior, Tabela 7, resultado do resfriamento brusco após o aquecimento nas temperaturas de $300,600,900$ e $1200^{\circ} \mathrm{C}$.

Tabela 8: Comparação do percentual de perda após o aquecimento e resfriamento brusco.

\begin{tabular}{c|c|c}
\hline \multirow{2}{*}{ Temperatura $\left({ }^{\circ} \mathbf{C}\right)$} & Referencial teórico (\%) & Análise realizada (\%) \\
\cline { 2 - 3 } & $\begin{array}{c}\text { Média do percentual de perda } \\
\text { (Aquecimento) }\end{array}$ & $\begin{array}{c}\text { Média do percentual de perda } \\
\text { (Aquecimento + Resfriamento) }\end{array}$ \\
\hline Concreto de referência & 00,00 & 00,00 \\
\hline 300 & 35,00 & 37,94 \\
\hline 600 & 55,00 & 69,05 \\
\hline 900 & 85,00 & 94,05 \\
\hline 1200 & 90,00 & 95,58 \\
\hline
\end{tabular}

Os dados são comparados aos resultados apresentados no referencial teórico [19, 20, 29], com as médias obtidas nestas faixas de fck's e temperaturas.

É possível observar os dados da Tabela 6 na (Figura 2), das quais apresentam o aumento da perda de resistência devido ao resfriamento brusco do concreto.

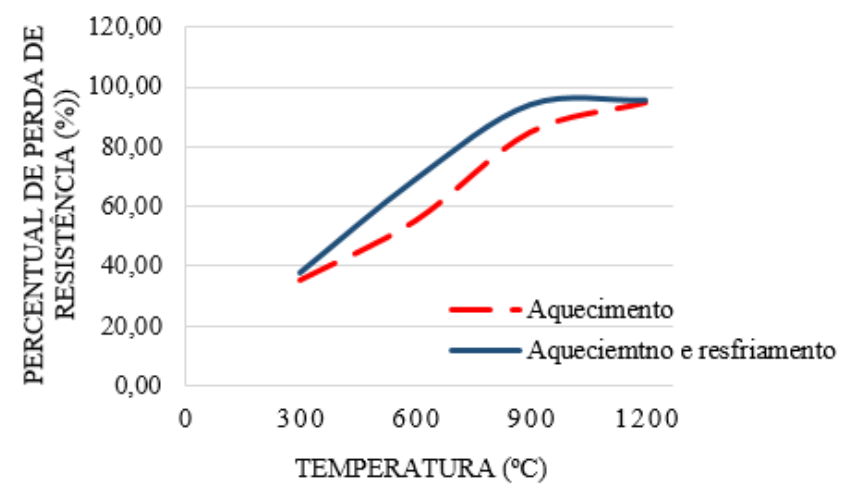

Figura 2: Aumento da perda de resistência devido ao resfriamento brusco do concreto.

A resistência dos concretos com fck de 25, 35 e 40MPa apresenta perda de resistência média de 37,94\% em $300^{\circ} \mathrm{C}$, ficando com coloração acinzentada. Em $600^{\circ} \mathrm{C}$, a resistência média decai para $69,05 \%$, com coloração rosa vermelhada ou cinza vermelhada. Já em 900 e $1200^{\circ} \mathrm{C}$, o concreto apresenta perdas entre $94,05 \%$ e $95,58 \%$, em média, ficando com coloração de cinza a vermelho. A coloração do concreto para cada fck varia com o aumento da temperatura (Figura 3), sendo aqui comparada aos concretos de referência em temperaturas ambiente para os fck's de 25, 35 e 40MPa. 


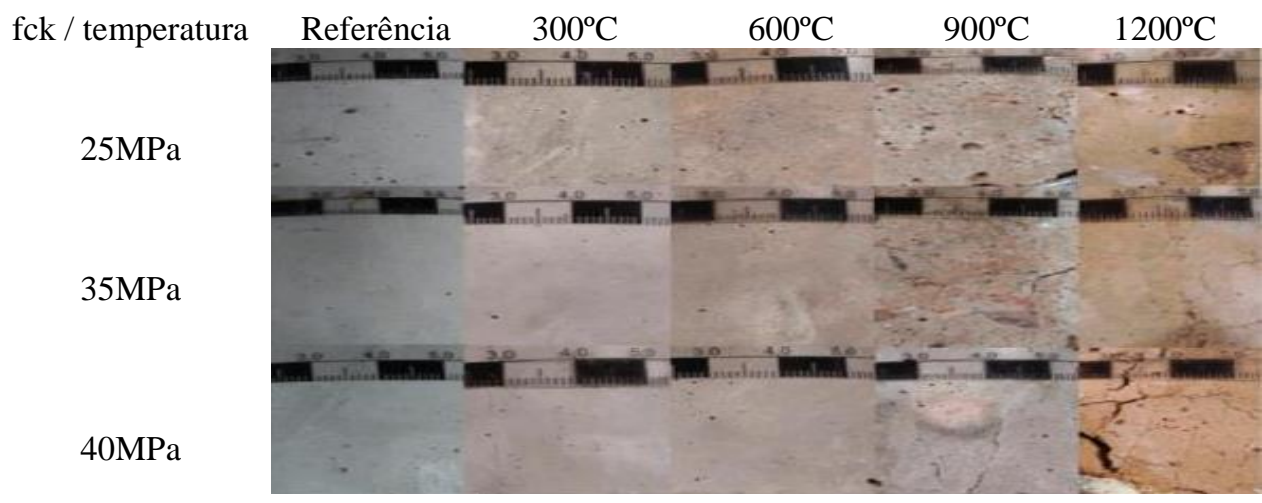

Figura 3: Variação de coloração com o aumento de temperatura para cada fck analisado.

Comparando os resultados aos referenciais teóricos [15, 20, 29, 12, 19], observou-se que a cor do concreto submetido a temperaturas elevadas está relacionada à resistência do mesmo. Quanto maior a temperatura, menor a resistência, com coloração próxima ao vermelho amarelado.

Para temperaturas de $300^{\circ} \mathrm{C}$, a coloração apresenta-se com tonalidade rosa avermelhada e o percentual de resistência residual média, ou seja, o quanto restou de sua resistência, em percentual é de 62,06\%. Em $600^{\circ} \mathrm{C}$ o concreto apresenta coloração cinza avermelhada, e o percentual residual médio é de 30,95\%. Na temperatura de $900^{\circ} \mathrm{C}$ a cor fica entre o rosa com tons avermelhados, sendo percentual residual médio de 5,95\%. Já para $1200^{\circ} \mathrm{C}$, a coloração tende ao amarelo, um vermelho amarelado, com a média percentual residual de $4,42 \%$.

\subsection{Surgimento de fissuras para o concreto com fck de $25 \mathrm{MPa}$}

A água evapora, causando pressões internas que empurram fragmentos de concreto. Para o concreto com fck de $25 \mathrm{MPa}$, a presença de fissuras é perceptível quando exposto às temperaturas de $900 \mathrm{e} 1200^{\circ} \mathrm{C}$, uma vez que os CP's apresentaram grandes deformações e fissuras.

Para a resistência de $25 \mathrm{MPa}$, as percepções do surgimento de fissuras iniciam com temperaturas maiores (Figura 4).

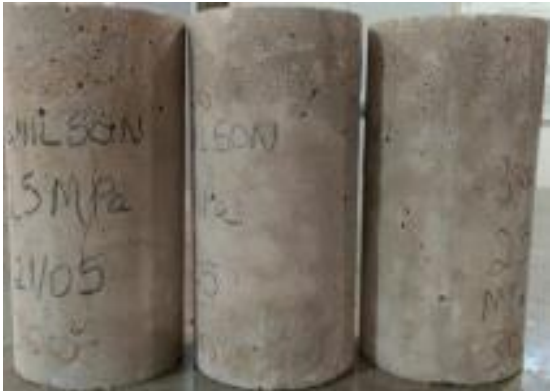

(a) $300^{\circ} \mathrm{C}$

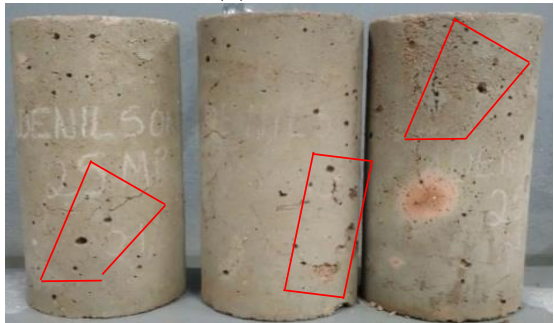

(c) $900^{\circ} \mathrm{C}$

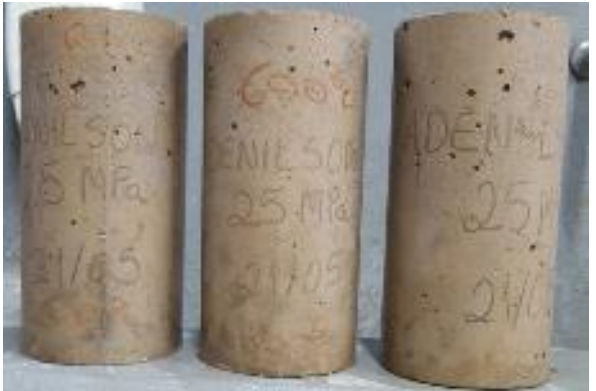

(b) $600^{\circ} \mathrm{C}$

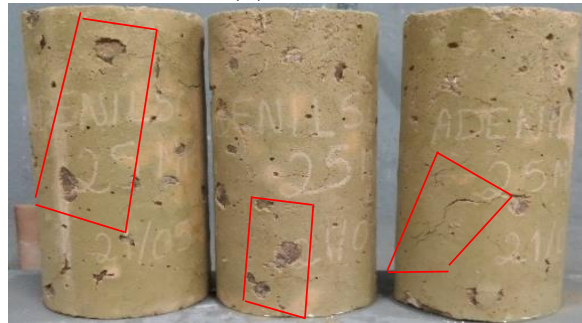

(d) $1200^{\circ} \mathrm{C}$

Figura 4: Surgimento de fissuras no concreto com fck de 25MPa, fissuras identificadas em vermelho. 
Assim como os demais, uma análise minuciosa deve ser realizada nas estruturas com esse fck, uma vez que os efeitos são iguais, independentemente da resistência. No entanto, não era objetivo do trabalho realizar avaliações na escala micro, apenas a análise visual dos CP's.

\subsection{Surgimento de fissuras para o concreto com fck de 35MPa}

A incidência de fissuras nos concretos com fck de $35 \mathrm{MPa}$ é mais perceptível se comparado ao concreto com fck de 25MPa. O fato explica-se devido à resistência do concreto ser maior.

As fissuras do concreto com fck de 35MPa é evidente devido à resistência do concreto ser maior. Quanto mais resistente, mais ocorre o desprendimento de fragmentos cimentícios e o surgimento de fissuras. Consequentemente, terá mais perda de resistência, não suportando as pressões internas nos poros e fissuras internas entre as fases de transições do cimento e agregado decorrente ao aquecimento e resfriamento.

Os resultados obtidos coincidem com estudos já realizados, conforme referencial teórico, os autores obtiveram resultados parecidos $[6,12,15,16,17,29]$.

A desfragmentação ou surgimento de fissuras pode ser identificada na (Figura 5).

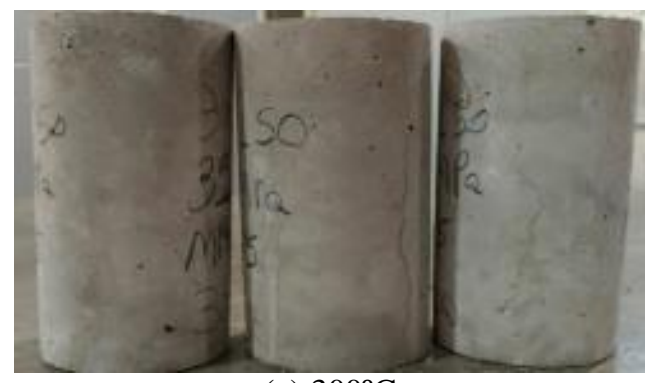

(a) $300^{\circ} \mathrm{C}$

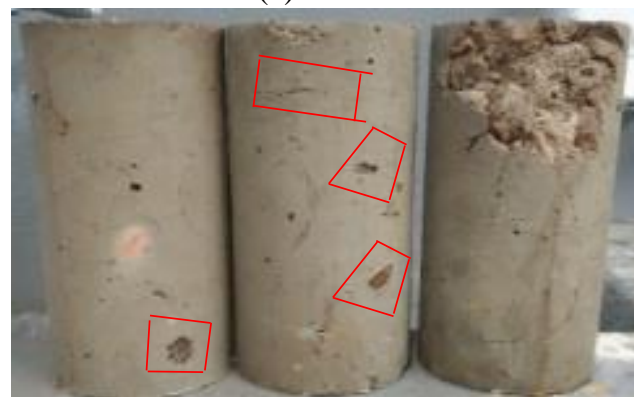

(c) $900^{\circ} \mathrm{C}$

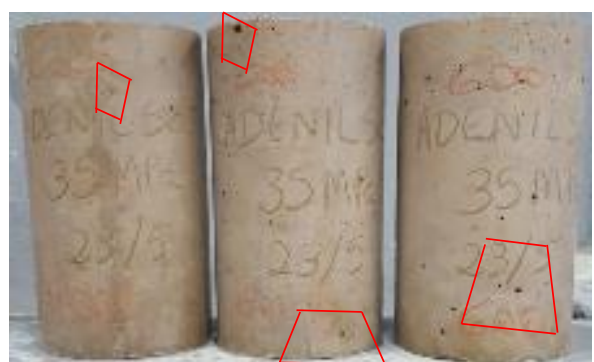

(b) $600^{\circ} \mathrm{C}$

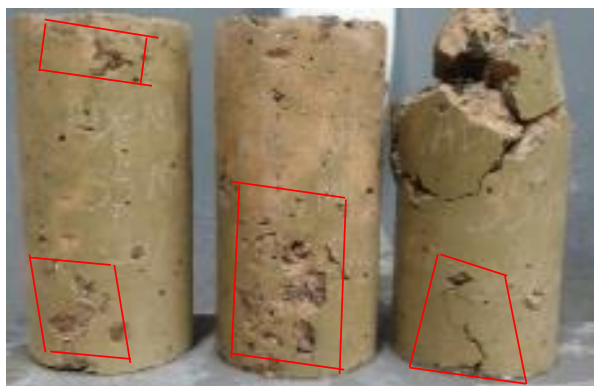

(d) $1200^{\circ} \mathrm{C}$

Figura 5: Surgimento de fissuras no concreto com fck de 35MPa, fissuras identificadas em vermelho.

\subsection{Surgimento de fissuras para o concreto com fck de $40 \mathrm{MPa}$}

$\mathrm{O}$ aparecimento de fissuras é mais perceptível no concreto com fck de 40MPa. A presença de pop outs ou, pequenos pipocamentos é visível em todas as faixas de temperaturas. Quando temos um concreto mais resistente como o de $40 \mathrm{MPa}$, caso submetido ao aquecimento e resfriamento brusco ele perderá resistência muito mais abrupto que um concreto com menor resistência, como o de $25 \mathrm{MPa}$.

Sendo assim, podemos dizer que, quanto maior a resistência característica do concreto, mais frágil ele é perante o fogo e ao processo de resfriamento brusco. Quando tem maior resistência, o concreto apresenta mais fissuras e rupturas após o choque térmico, pois não suporta as pressões internas.

Isso é observado no concreto de fck $40 \mathrm{MPa}$ quando aquecido em $300^{\circ} \mathrm{C}$ e submetido ao resfriamento. Em $300^{\circ} \mathrm{C}$ apresentou fissurações maiores e possíveis deslocamentos de pedaços do concreto (Figura 6). 


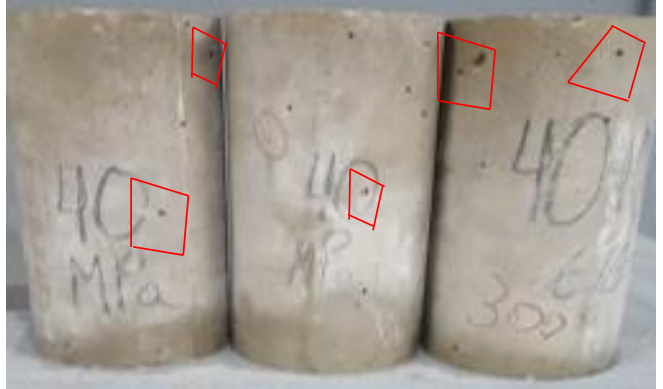

(a) $300^{\circ} \mathrm{C}$

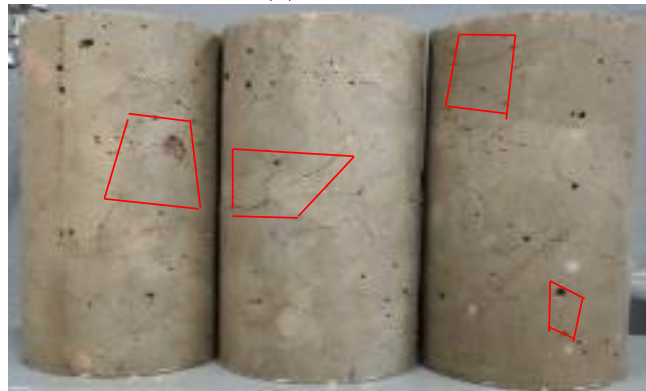

(c) $900^{\circ} \mathrm{C}$

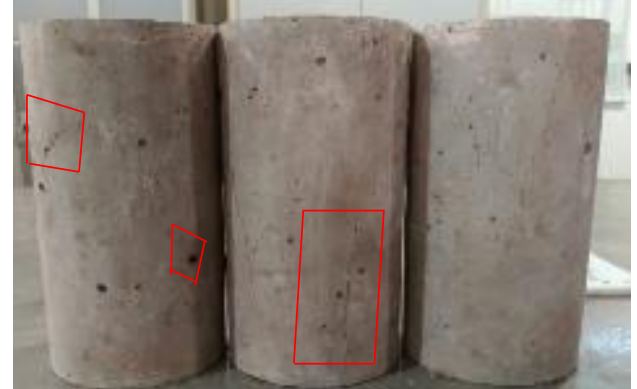

(b) $600^{\circ} \mathrm{C}$

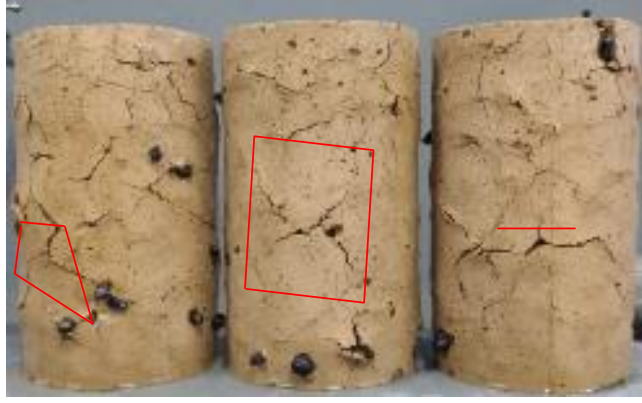

(d) $1200^{\circ} \mathrm{C}$

Figura 6: Surgimento de fissuras no concreto com fck de $40 \mathrm{MPa}$, com fissuras identificadas em vermelho.

\section{DISCUSSÃO}

Os resultados demostram que os efeitos do resfriamento devem ser considerados nos quesitos de segurança contra incêndio das estruturas de concreto. É perceptível que a partir de $300^{\circ} \mathrm{C}$ a resistência apresenta perdas consideráveis, com percentuais de perdas na ordem de $37,94 \%$ em média para os fck's de 25,35 e $40 \mathrm{MPa}$. Em temperaturas como $600^{\circ} \mathrm{C}$, o decaimento da resistência é maior, com percentual de perda chegando a $69,05 \%$ em média. Para faixas de 900 a $1200^{\circ} \mathrm{C}$, os concretos apresentam percentuais de perdas na resistência em torno de 94,05 a $95,58 \%$ em média. Com relação ao aumento de temperatura, acima de $600^{\circ} \mathrm{C}$, o processo de evaporação d'água, surgimento de fissuras e a perda de resistência ocorrem rapidamente, inviabilizando o concreto.

Para os concretos com fck de 25 e $35 \mathrm{MPa}$ em $300^{\circ} \mathrm{C}$, as alterações são imperceptíveis. No entanto, para os fck's de 25,35 e $40 \mathrm{MPa}$ em $600^{\circ} \mathrm{C}$, as alterações são visíveis, com percentual de perda de resistência chegando a $69,05 \%$ em média para os fck's. Em todos os CP's aquecidos e resfriados bruscamente, ocorreu a queda da resistência, sendo o decaimento médio para a temperatura de $900^{\circ} \mathrm{C}$ com aproximadamente $94,05 \%$, média para os fck's de 25,35 e $40 \mathrm{MPa}$. Para a exposição em $1200^{\circ} \mathrm{C}$, o percentual de perda média é cerca de 95,58\% para os mesmos fck's, se comparando ao valor inicial de resistência à compressão aos 28 dias do concreto de referência.

Com o resfriamento brusco da estrutura, intensificou a perda, uma vez que os dados do referencial teórico, apenas com o aquecimento, o percentual de perda é entre $35 \% \mathrm{em} 300^{\circ} \mathrm{C}$ a $90 \%$ em $1200^{\circ} \mathrm{C}$. Entretanto, com o resfriamento, os percentuais aumentam, variando de $37,94 \% \mathrm{em} 300^{\circ} \mathrm{C}$ a $95,58 \% \mathrm{em} 1200^{\circ} \mathrm{C}$. Portanto, são perceptíveis as alterações na resistência do concreto após o aquecimento e resfriamento brusco.

Percebeu-se ainda que quanto maior for à resistência do concreto, mais ele perde resistência quando submetido ao aquecimento e ao choque térmico por resfriamento brusco. O concreto com fck de $35 \mathrm{MPa}$, por exemplo, quando exposto às temperaturas de 300 e $600^{\circ} \mathrm{C}$ teve perda maior que o concreto de $25 \mathrm{MPa}$ exposto às mesmas temperaturas. Entre 900 e $1200^{\circ} \mathrm{C}$, a perda é semelhante para os concretos de fck 25 e 35MPa. No aquecimento, as propriedades do concreto e agregado são alteradas, permitindo a sua expansão e deformação. O mesmo fenômeno foi comprovado por [9, 12].

Esse efeito contribui para o surgimento de fissuras no interior do concreto, que, por sua vez, devido a esforços internos o material é separado, deslocado. Toda água é evaporada entre 600 e $900^{\circ} \mathrm{C}$, fazendo com que as pressões internas sejam cada vez maiores. No instante em que o concreto é resfriado, ocorre o surgimento de fissuras, fazendo com que a resistência à compressão venha a reduzir a resistência.

O aumento de temperatura favorece para variação de coloração do concreto. Esta percepção é possível ser verificada visualmente, sendo, portanto, correlacionada com a perda de resistência. Quanto maior for à temperatura de exposição, mais amarelado será o concreto, tendo sua resistência reduzida. 


\section{CONCLUSÕES}

A rigidez do concreto favorece o surgimento das fissuras e o lascamento do concreto após o aquecimento e resfriamento. Sendo assim, quanto maior a resistência característica, maior será a tendência ao surgimento de fissuras quando o concreto é exposto ao calor e resfriamento brusco.

Os concretos com fck de 25, 35 e 40MPa apresentaram perda de resistência após o resfriamento brusco. $\mathrm{O}$ concreto com fck de $25 \mathrm{MPa}$ teve redução na resistência proporcional ao aumento de temperatura, já os demais concretos, apresentaram redução na resistência mais gradual e logarítmica.

Conforme dados apresentados na Tabela 5, que trata do percentual de perda após o aquecimento e resfriamento, existe diferença de resistência quando aquecido e resfriado. A diferença de maior perda de resistência quando resfriado foi aproximadamente de $2,94 \%$ em média para os concretos aquecidos a $300^{\circ} \mathrm{C}$, e em torno de $14,05 \%$ em média quando aquecidos a $600^{\circ} \mathrm{C}$, por volta de $9,05 \%$ em média a $900^{\circ} \mathrm{C}$ e cerca de $5,58 \%$ em média a $1200^{\circ} \mathrm{C}$.

Quanto ao surgimento de fissuras nos CP's, quanto maior a resistência do concreto e as temperaturas de incêndio, mais lascamento e novas fissuras ocorreram, consequentemente, menor deve ser a resistência do concreto após seu resfriamento brusco com a água.

Portanto, verifica-se que durante uma ocorrência de incêndio, o procedimento de jogar água para resfriar e combater pode comprometer uso da edificação para fins estruturais.

Os efeitos do aquecimento e resfriamento podem, portanto, ser minimizados com a utilização de fibras de polipropileno, sendo este tema uma sugestão para pesquisas futuras na área de estruturas de concreto submetidas ao incêndio e engenharia de segurança contra incêndio das estruturas.

\section{AGRADECIMENTOS}

Ao Centro Universitário Católica de Santa Catarina por disponibilizar os materiais e equipamentos para o preparo, aquecimento e rompimento dos corpos de prova. Aos técnicos do laboratório de Materiais de Construção em Joinville (Robson Rosa) e Jaraguá do Sul (Deise Maria Demarchi) e ao acadêmico Valdir Luiz Cipriano Neto, pois auxiliaram no preparo, aquecimento e rompimento dos corpos de prova. Ao engenheiro Fernando Cesar, pois auxiliou na redação do artigo. Ao Prof. Dr. Luiz Veriano Oliveira Dalla Valentina, que prontamente aceitou o convite em compor a banca examinadora do TCC, texto base para submissão do presente artigo. A Priscilla Pereira, pessoa que compartilhou suas experiências e apoio motivacional. A revista Matéria por proporcionar a oportunidade de publicar o artigo.

\section{BIBLIOGRAFIA}

[1] ABNT NBR (2001), NBR-14432: Exigência de resistência ao fogo de elementos construtivos de edificações-Procedimentos. Rio de Janeiro, ABNT - Associação Brasileira de Normas Técnicas.

[2] BOLINA, F. L., "Avaliação experimental da influência dos requisitos de durabilidade da segurança contra incêndio de protótipos de pilares pré-fabricados de concreto armado", Dissertação de M.Sc - UNISINOS, São Leopoldo, RS, 2016.

[3] BRENTANO, T., A proteção contra incêndio no projeto de edificação. 3. Ed. Porto Alegre: Edição do autor, 2015.

[4] BRENTANO, T., Instalações Hidráulicas de Combate a Incêndio nas Edificações. 5. Ed. Porto Alegre, Edição do autor, 2016.

[5] CENIPA. Centro de Investigação e Prevenção de Acidentes Aeronáuticos. Comando da Aeronáutica. Acidente aeronáutico TAM 3054. Relatório final A-Nº7/CENIPA/2009. Brasília, pp. 1-122. 2009.

[6] CARDEAL, W. J., "Combate a incêndio estrutural: um estudo sobre o uso de câmaras de imagem térmica pelo Corpo de Bombeiros Militar de Santa Catarina”, Monografia Formação de Oficiais - CBMSC, Florianópolis, SC, 2015.

[7] CARDOSO, É. K., "Atuação da fisioterapia às vítimas da Boate Kiss: a experiência de um Hospital de Pronto-Socorr", Hospital de pronto socorro, pp. 133-136, Porto Alegre, Rio Grande do Sul, 2014.

[8] COSTA, C. N., FIGUEIREDO, A. D. de, SILVA, V. P., "Fenômeno do lascamento ("spalling") nas estruturas de concreto armado submetidas a incêndio - uma revisão crítica", In: $44^{\circ}$ Congresso Brasileiro de Concreto, Belo Horizonte, Minas Gerais, Brasil, 2002. (A).

[9] COSTA, C. N., SILVA, V. P. "Estruturas de concreto armado em situações de incêndio", In: XXX Jornadas Sul-Americanas de Engenharia Estrutural, Brasília, Distrito Federal, Brasil, 2002. (B). 
[10] EHRENBRING, H. Z., ORTOLAN, V., BOLINA, F., et al., "Avaliação da resistência residual de lajes alveolares em concreto armado em uma edificação industrial após incêndio”, Revista Matéria, v. 22, n. 03, p.110, Mai. 2017.

[11] FERNANDES, I. R., Engenharia de segurança contra incêndio e pânico. Curitiba, PR, CREA-PR, 2010.

[12] FERNANDES, B., GIL, A. M., TUTIKIAN, B. F. "Microestrutura do concreto submetido a altas temperaturas: Alterações físico-químicas e técnicas de análise”, Revista IBRACON de estruturas e materiais, v.10, n.4, pp.838-863, Ago. 2017.

[13] GOMES, T., "Projeto de prevenção e combate a incêndio", Trabalho de Conclusão de Curso - UFSM, Santa Maria, RS, 2014.

[14] GLUER, Laura M. "Comunicação e poder na cobertura jornalística das crises da aviação: uma análise dos acidentes TAM 3054 e AF 447 na revista veja”, Tese de D.Sc - PUCRS, Porto Alegre, Rio Grande do Sul, 2010.

[15] GROCKOSKI, B., "Estudo da relação entre o fenômeno de calcinação e a redução da resistência do concreto armado em situações adversas”, Revista FLAMMAE, v. 4, n.9, pp.119-142, Jun. 2018.

[16] HAGER, I. "Behaviour of cement concrete at high temperature". Bulletin of the polish academy of sciences techinical sciences, v.61, n.1, pp.145-154, 2013.

[17] KHOURY, G. A., "Effect of fire on concrete and concrete structures", Concrete construction, n. 2, pp.429-447, 2000.

[18] KODUR, V.K.R., AGRAWAL, A., "Effect of temperature induced bond degradation on fire response of reinforced concrete beams", Engineering Structures, v.142, pp.98-109, July.2017.

[19] LORENZON, A., “Análise da resistência do concreto após exposição a altas temperaturas". Trabalho de Conclusão de Curso - UTFPR, Pato Branco, PR, 2014.

[20] MORAlES, G., CAMPOS, A., FAGANELlO, A. M. P., “A ação do fogo sobre os componentes do concreto”, Seminário: Ciências Exatas e Tecnológicas, Londrina, v. 32, n.1, p. 47-55, Mar. 2011.

[21] MELÃO, A. R., SILVA, V. P., “Equivalência entre incêndio-padrão e curvas paramétricas aplicados a estruturas de aço", In: Congresso Latino-Americano da Construção Metálica, São Paulo, SP, 02-04 Set. 2014.

[22] NIEDERAUER, Ana Paula. O que se sabe sobre incêndio que derrubou prédio no centro de SP. ESTADÃO, São Paulo, 05 abr. 2018. Disponível em: <http://saopaulo.estadao.com.br/noticias/geral,o-que-se-sabesobre-incendio-que-derrubou-predio-no-centro-de-sp,70002291550>. Acesso em: 05 abr. 2018.

[23] RIBEIRO JR., Paulo Lucio. Estruturas de concreto: Verificação e dimensionamento em situação de incêndio, 1. Ed. São Paulo, Porto de Ideias, 2018.

[24] REOLOM, M., ITALIANI, R., VEIGA, E., et al., Incêndio atinge o museu da língua portuguesa. ESTADÃO, São Paulo, 21 dez. 2015. Disponível em: <http://saopaulo.estadao.com.br/noticias/geral,incendio-atingeo-museu-da-lingua-portuguesa,10000005428>. Acesso em: $17 \mathrm{dez} .2017$.

[25] SCOTTON, J. A., SILVA, B.V., et al., "Análise da resistência residual de aderência aço concreto após a exposição a altas temperaturas”, In: 55 Congresso Brasileiro de Concreto, Gramado, Rio Grande do Sul, 29 Outubro a 01 Novembro 2013.

[26] SEITO, A. I., et al. A Segurança contra incêndio no Brasil. São Paulo, Projeto Editora, 2008.

[27] SILVA, D. S., "Propriedades mecânicas residuais após incêndio de concretos usados na construção civil na grande Florianópolis”, Dissertação de M.Sc - UFSC, Florianópolis, Santa Catarina, 2009.

[28] SILVA, V. P., et al., Prevenção contra incêndio no projeto de arquitetura. Rio de Janeiro, IABr/CBCA, 2010.

[29] SILVA, J. S., SÁ, M. V.V. "Concreto de alta resistência submetido a diferentes temperaturas", In: 55 Congresso Brasileiro de Concreto, Gramado, Rio Grande do Sul, 29 Outubro a 01 Novembro 2013.

[30] SILVEIRA, M. V. "Segurança contra incêndio e pânico: um estudo sobre sistemas destinados ao abandono seguro de ocupantes em edificações elevadas", Monografia Formação de Oficiais - CBMSC, Florianópolis, $\mathrm{SC}, 2015$.

[31] YERMAK, N., PLIYA, P., BEAUCOUR, A. L., et al., "Influence of steel and/or polypropylene fibres on the behaviour of concrete at high temperature: Spalling, transfer and mechanical properties", Construction and Building Materials, v.132, pp. 240-250, Dec. 2017. 
[32] WANG, F., WANG, M., HUO, J., "The effects of the passive fire protection layer on the behavior of concrete tunnel linings: A field fire testing study", Construction and Building Materials, v.69, pp.162-170, Oct. 2017.

\section{ORCID}

Adenilson Roberto Coelho

https://orcid.org/0000-0003-0499-0382

Geórgia Cristina Roveda Campos

https://orcid.org/0000-0002-3326-8850

Carine Cardoso dos Santos

https://orcid.org/0000-0002-6175-0142

Helena Ravache Samy Pereira

https://orcid.org/0000-0002-2408-1648

Tássia Furlaneto

https://orcid.org/0000-0002-5454-4869 